\title{
MALE CIRCUMCISION IN INDIA: SOME CONSIDERATIONS FROM THE WEST
}

\author{
Mirko Daniel Garasic \\ Centre for Human Bioethics, Monash University, Melbourne, Australia and \\ Center for Ethics and Global Politics, LUISS University, Rome, Italy \\ Email: mirko.garasic@monash.edu; mgarasic@luiss.it
}

\begin{abstract}
In this work, I will analyse why Indian authorities find it so difficult to publicly acknowledge the medical benefits of Male Circumcision (MC). In doing so, the medical evidence in favour of the practice, as well as the moral duties that governing authorities have towards their citizens shall be taken to the fore. In addition to this argument, a brief explanation of the cultural dimension that refuses to evaluate the medical dimension of $M C$ a priori shall be taken into account and, in relation to that, a parallel with the past and present Western tradition will be drawn, putting forward the conclusion that both contexts do not provide satisfactory justification for banning MC nor more relevantly for the Indian scenario can any cultural background represent a convincing argument against the public acknowledgement of the medical advantages provided by MC.
\end{abstract}

Key words: Anti-Semitism, HIV, India, Informed Consent, Islamophobia, Male Circumcision, Public Policies, STDs

INTRODUCTION: The intention of this work is to point out how -in India as well as in a growing number of Western countries the hostility against the implementation of Male Circumcision (MC henceforth) is not based on medical evidence but rather on religious and cultural grounds. Despite the fact that in recent years plenty has been written on the therapeutic value of MC to contrast, among others Sexually Transmittable Diseases (STDs), HIV/AIDS ${ }^{1}$ an increasingly worrying shadow in Indian society, the practice still finds very little support from the Indian medical community. However, as rightly pointed out by Chandhiok and Gangakhedkar in their article "The New Evidence on Male Circumcision: An Indian Perspective", ${ }^{2}$ at the moment the number of Indian citizens affected by the HIV virus is relatively low, but, it is reasonable to believe that, if not properly contrasted at this early stage, the number will multiply exponentially in the coming decades, resulting in a damaging impact not only for the sufferers of the illness and their families but also for Indian society as a whole, as this will increase the costs for the Health Care System dealing with HIV/AIDS. There is reasonable ground to believe that implementing MC would help reducing the risk of a future epidemic in India and, as a recent study underlined, ${ }^{3}$ the disclosure of the beneficial feature of MC could indeed increase the level of awareness among people and their willingness to adopt such a practice also on nonreligious grounds.

In this work, I will analyse why Indian authorities find it so difficult to publicly acknowledge the medical benefits of MC. In doing so, the medical evidence in favour of the practice, as well as the moral duties that governing authorities have towards their citizens shall be taken to the fore. In addition to this argument, a brief explanation of the cultural dimension that refuses to evaluate the medical dimension of $\mathrm{MC}$ a priori shall be taken into account and, in relation to that, a parallel with the past and present Western tradition will be drawn, putting forward the conclusion that both contexts do not provide satisfactory justification for banning MC nor -more relevantly for the Indian scenario- can any cultural background represent a convincing argument against the public acknowledgement of the medical advantages provided by MC.

POLITICAL UNCERTAINTIES REGARDING MC IN INDIA: IS IT JUSTIFIABLE? In the past decade, particularly in Sub-Saharan Africa, MC has been implemented by the local governments as an additional measure to prevent the ever-growing number of cases of HIV/AIDS. Policies have been used to raise awareness among adult males to undergo the surgical operation for the love of their dear ones and their community and the results of these campaigns have been fairly encouraging. ${ }^{5}$ Despite this global trend to affirm the medical legitimacy for the establishment, once 
and for all, of MC as an indisputable form of prevention for one of the most affecting illness in NonWestern countries, India remains contrary to a public acknowledgement of the constantly increasing data that supports the carrying out of $M C$ as a valid form of prevention against HIV/AIDS. In fact, as pointed out by Madhivanan and Krupp,

"the Government of India has been reluctant to approach an issue that promises to be controversial among conservative Hindus. ${ }^{6}$ It has been suggested that at times, circumcision status may even have been used to identify people's religious affiliation during communal riots. ${ }^{7}$ Popular wisdom holds that even the mention of $M C$ in some communities will trigger sectarian violence. Predictably, some opponents have argued that the greater good of society must be protected by withholding information about MC from the population." ${ }^{8}$

It seems that the Hindus -be it for their political presence (Hinduism is the most prominent religion in India) or for their strong historical clash with Islam- are the one group that has raised more problems against the adoption of MC as a preventive tool against HIV ${ }^{9,9 a}$. For example Kounteya Sinha writes:

"Sometime back, when executive director of Geneva-based Global Fund to fight AIDS, Richard Feachem, made a statement in Paris that he expected the epidemic to grow faster among Hindus because they didn't practise circumcision, he received thousands of hate mails from the Hindu community". ${ }^{10}$

This attitude towards the possible implementation of a procedure that could benefit Indian citizens' health remains deeply controversial and raises many points that need attention. Due to a lack of space, in this work I will not be able to cover all of them, but I shall instead focus only on three of them.

The first point underlines the moral duty of authorities. They must do anything in their power to avoid the suffering of people and the spreading of the disease. After all, as rightly pointed out by Prabhakara in his book Professional Medical Ethics, it should never be forgotten that:

"No groups of individuals should be discriminated in the context of HIVIAIDS."

And also:

"All individuals and all communities should have availability of information necessary to make good and necessary decisions about their health including how to avoid HIV infection."11

In this light, it would be reasonable to affirm that it is the duty of the authorities (in the specific case Indian authorities) to at least acknowledge publicly the preventive value of $M C$ against the spreading of HIV. Only once ensured a satisfactory level of awareness among the population, it would be possible to consider the decision of the parents or the single individual to undergo -or not- the MC procedure as a proper informed choice.

The second point would focus on the traditional Indian non-individualistic perspective in Medical Ethics. In his article "Medical ethics in India: ancient and modern", Francis highlights how according to the Vedas (4000 BC to $1000 \mathrm{BC}$ ), the call to love your neighbour as yourself is

"because thy neighbour is in truth thy very self and what separates you from him is mere illusion."12

This acknowledgement should perhaps push us to put aside the centrality of autonomy as used in Western context by some authors ${ }^{13}$ to justify their prejudice against MC. On the contrary, we might be inclined to give relevance to the common outcome of the implementation of MC: allowing individuals to undergo the surgery would benefit any member of the Indian society despite his religious background (be it Hindu, Muslim, Sikh, and Buddhist, Jewish or of any other faith and belief), significantly cutting down costs and -most importantly- risks. Thus, once accepted the medical value of $\mathrm{MC}$, it could be argued that, in some sense, this precautionary intervention is implicitly encouraged in Indian tradition.

The third and final point would focus on the contrasting attitude that mothers have towards $\mathrm{MC}$ 
after having been isolated from that very political indoctrination that deprives them from the exposure to the medical benefits of the practice. It is interesting to note that, in a recent study conducted in India, ${ }^{14}$ it was shown that, even in a low educated, prevalent non-Muslim community, once having received a proper explanation of the practice -including the advantages produced by MC and its correlated STDs risk avoidance- the vast majority of mothers $(81 \%)$ were inclined to make their children undergo the operation. Only $1 \%$ of the interviewed women were still against $M C$ in a convinced way. These are, quite clearly, neat numbers over the importance of informing the population on the medical impact of MC but, unfortunately, a more in-depth examination of these data goes beyond the scope of this paper. However, I would like to put forward, for what it counts, a parallel interpretation of those numbers through an analysis of why the male community might be more reluctant to accept the practice.

There is little doubt that -from a strictly physical point of view- fathers share with their sons the very part of the body subject to the potential operation, and, as a result, it is understandable to see why a father could perceive MC as a way of spacing out himself from his child. After all, the same logic (with the reversed argument) is used by the defenders of MC. In addition to the subjective perception though, males also do not want to feel the social pressure to be the direct cause for change to take place within the community at large. In other words, they do not want to be labeled the weak link of the tradition by allowing their own son to undergo an operation that will make the child somehow more detached from his ancestors -at least in pure physical terms. Females on the contrary, do not undergo this psychological challenge, and thus mothers have a more detached and objective view on the medical factors that should indeed be considered for the benefit of the individual child as well as the community as a whole.

CULTURAL IMPEDIMENTS FOR MC IN INDIA: Despite the considerations highlighted above, in the Indian context the main critique moved against the implementation of $M C$ as a therapeutic tool capable to avoid the spreading of HIV especially in poorer and less educated contexts- would affirm that the problem with this solution is related to its "cultural" threat. ${ }^{15}$ The defenders of this position would argue that by applying $\mathrm{MC}$ to all the new borns in India, this will end up undermining the cultural identity of the non-Muslims (or non-Jews) Indians. This assertion gives rise to two points worthy of consideration: the first point concerns the fact that -differently from the acknowledgements reported in this work- the focus of $M C$ is strictly related only to the Muslim identity. However, this is a strongly distorted (and scientifically inaccurate) way of categorising and defining the practice. I believe that it is so for political reasons that want to prevent the introduction of the practice by focusing on the "prevail of the Muslim cause", initiating in this way a fear in the Hindu majority in the country. What could perhaps function as a good viaticum against this fear, could be the parallel acknowledgement of the practice as part of the Judaic tradition as well as even if in a very limited way- of Christianity.

The second point would make us question to what extent is it possible to assert that the implementation of certain features not implicitly prescribed by one culture, can be considered to be a way of affirming a loss of one's culture instead of a restructure in accordance to more recent changes. Today's India represents -with its increasingly important visibility and impact at global level- an example for many. In this age of confusion and tendency to close up against 'the others' in Europe as anywhere else in the world- India's status of the biggest democracy in the world could well function as a way forward for the hopes of humanity. Having the courage to live its multiculturalism to the fullest, India's politicians should have the strength to implement a policy on $\mathrm{MC}$ that will pass on the message that India is capable of acting in the best interest of all its citizens despite their religious, cultural or ethnical backgrounds.

SOME PARALLELISM WITH THE WEST: In relation to the "cultural" aspect behind the refusal of a mass-implementation of $M C$ in India, it would probably be interesting to note the different treatment that the practice has had in a culturally different setting. In the specific, I shall briefly describe the historical attitude towards $\mathrm{MC}$ in Europe, and the contemporary stand that the Western world has in relation to it; especially in the framework of rising intolerance towards "the different" that currently governs Europe. This parallelism of course shall not function as a form of enlightenment for the Indian situation, but rather, it should help us putting this delicate debate in a wider and more global context. 
In hardcore fortresses of Roman Catholicism such as Italy or Spain -places where the persecution of Jews (and in a more limited way that of Muslims) has had a long history based on religious grounds MC has never been encouraged and, only recently, it became tolerated. With the awareness that ostracism against the different, the other has been a sad but true constant in human history in different times and places, it is reasonable to think that, as in the case of Muslims in India, ensuring that the procedure was performed "only" by Jewish individuals was a very practical way to quickly recognise the Jew from the Christian when some discriminatory practice be it expulsion or mockery- had to take place.

The stigmatisation of the Jewish traditional MC (brit milah) has -among its numerous representatives- Justin of Caesarea, a deeply influential figure as a martyr and one of the Fathers of the Church. In line with a gradual and often intentional- detachment from Judaism that Christianity has increasingly undergone after the death of all its [at least] Jewish born founding forefathers, in his Dialogue with Triphone, ${ }^{16}$ he attacks the Jewish MC by contra posing the physically circumcised people (the Jews) with the spiritually circumcised ones (the Christians). ${ }^{17}$ In a way thus, it could be argued that MC was indeed needed in Europe, but only in order to remind Christians to be -in the eyes of some of them- the evolution of an updated creed. In line with the intention of not wanting MC to become a popular practice among Christians, since the Middle Ages it gained ground in Europe the belief -thanks to the well-fed anti-Judaic paranoia supported, fed and spread by the Church- that the Jews needed to sacrifice Christians regularly in order to (besides other nonsensical arguments still recycled in nowadays' versions of anti-Semitism) stop haemorrhages caused by the brit milah. ${ }^{18}$ This intolerant approach to MC reached its peak when the Roman Catholic Church decided to ban it and make it a mortal sin that would result in "loss of eternal salvation". ${ }^{19}$

However, within Western countries where the influence of Roman Catholicism was not as strong (particularly in the USA and Australia), towards the end of the $19^{\text {th }}$ Century the practice of MC became increasingly common reaching its peak in the 60 's. ${ }^{20}$ This was due to a number of pseudoscientific beliefs concerning MC that ranged from the imaginative claim that it helped prevent masturbation (a huge taboo in the Victorian era) ${ }^{21},{ }^{21 a}$ to the more accurate belief that MC had hygienic value. Of course not everyone within the Christian-directed Western societies was ready to give in to the idea that 'dirty' people such as the Jews or the Muslims could be systematically and convincingly- be practising an hygienic ritual. ${ }^{22}$ Since the 70 's however, the percentage of MC in Australia has dropped significantly, ${ }^{23}$ while the drastic increase of the number of circumcised males in Europe -due to the wave of Muslims immigrants- has opened the door to new forms of discrimination inexplicitly claiming to preserve the "purity" of the European value through a misuse of the notion of rights and autonomy. As a result, in more recent years, MC has gradually come under attack as a mere mythological feature that, in truth, does not rely on any medical evidence to justify its implementation. ${ }^{24}$ Most notably, the attempted ballot in San Francisco aimed at fully outlawing infant MC as well as the temporary dis-allowance for the practice in Germany last June, ${ }^{25}$ showed how vivid is this trend. Despite the lack of credibility of such an accusation, this "pseudo-cultural" battle has managed somehow to undermine the medical evidence of the efficacy of $\mathrm{MC}$ as a preventive measure against HIV, contributing most probably to the drastic drop of toleration and practice of MC in Western countries.

CONCLUSION: To conclude, this paper has drawn a parallel between the East and the West in relation to a millenary procedure such as MC. It did so, with the intention of underlining that, what is common between all those positions intolerant to MC in both India and the West is their need to deal only approximately with the medical evidence that the practice carries with it. On the one hand, Indian authorities are sceptical over officially affirming that $\mathrm{MC}$ can function as a reliable, medically proven preventive against the spreading of deadly illnesses STDs more in general and HIV/AIDS more specifically for their fear of the cultural impact that such a claim could produce. On the other hand, some of the most fervent attackers of the legitimacy of MC in the Western world also (but not as explicitly of course) use a bias "cultural-meter" to affirm that MC is against the rights of children for example although forgetting to apply the same principle of uncompromisingly preserve the physical integrity of the child in widely accepted comparable practices such as earpiercing or vaccination. It seems obvious thus, that these attacks have as their ultimate aim that to de-legitimise the non-Christian traditions by redefining "Western values" as only and purely 
ascribable to the Christian rituals.

This commonality between the two situations, with all their unconvincing justifications for not accepting MC, should lead us to affirm with no hesitation that given the continuously growing medical evidence that shows the direct and indirect advantages produced by having a circumcised male population MC should at least be tolerated if not encouraged. Cultural differences cannot be considered as a sufficient justification when the health of the population is at stake, and for this reason it seems sensible to affirm that (even if the spreading of such news could produce some tension) Indian authorities should not delay any further the communication of the MC's proven benefits to the public. After all, this very delicate issue is related to the health of the whole population and therefore, the resulting discussion over its legitimacy should put forward the medico-ethical point of view of a nation. In order for such an opinion to be democratically expressed, however, the population needs to be given the scientific data. Only in this scenario we would be talking about a truly informed choice on the matter.

Surely the topic is sensitive and some politically related problems might arise from the disclosure of the medical evidence related to MC. However, if some protests might occur as a result of this political decision, the competent political authorities will have to face it and deal with it only as a political problem, because the potential political impact of the revelation of the medical evidence highlighted in this work cannot represent a sufficient reason to refrain from communicating vital information to the Indian people, who deserves to know all the available data to then be able to truly make a free and competent choice with their lives. Thus, the Indian Government may inform the public of benefits of $M C$ and give the public an option for it.

\section{REFERENCES:}

1. WHO and JOINT UN PROGRAM ON HIV/AIDS. Male Circumcision: Global Trends and Determinants of Prevalence, Safety and Responsibility. (December 2007) Report. Available at: http://whqlibdoc.who.int/publications/2007/978924156169 eng.pdf

2. Chandhiok $\mathrm{N}$ and Gangakhedkarb R. The New Evidence on Male Circumcision: An Indian Perspective, Reproductive Health Matters 2007, 15\& 29: 53.

3. Dandona L, Dandona R, Kumar GA, Brahmananda GR, Abdul AM, Mushtaq GA, Ramgopal SP, Akbar M, Sudha T and Lakshmi V. Risk factors associated with HIV in a population-based study in Andhra Pradesh state of India. International Journal of Epidemiology 2008, 1-13.

4. Circumcision: It suits Hindus also, available at: http://articles.timesofindia.indiatimes.com/2005-08-04/india/27843351_1_circumcised-men-hivrates-richard-feachem

5. Gray RH, Kigozi G, Serwadda D, et al. Male circumcision for HIV prevention in men in Rakai, Uganda: a randomized trial. The Lancet 2007, 369: 657-666.

6. It is important to point out that, even if in a less harsh and direct way until now, Sikhism has an even higher potential of resistance towards MC on religious ground. In fact, while Hindu's sacred tests do not explicitly ban the practice of MC, in the Guru Granth Sahib, an explicit restriction against it is written. Available at:

http://www.srigranth.org/servlet/gurbani.gurbaniAction=Page \&Param=477\&english=t\&id=21608\# $\underline{121608 .}$.

In particular p.140 and p.477.

7. Chandhiok N and Gangakhedkarb R, Op. Cit. 
8. Madhivanan P and Krupp K. Doesn't the public have the right to know that male circumcision protects against HIV? Indian Journal of Medical Ethics 2009, 6(1):5.

9. Moses S, Bailey RC and Ronald AR. Male circumcision: assessment of health benefits and risks. Sex Transm Infect 1998, 74: 368-373.

9a. Castellsagué X, Xavier Bosch F, Muñoz N, Meijer CJLM, Shah KS, Silvia de Sanjosé S, ElufNeto J, Ngelangel CA, Chichareon S, Smith JS, Herrero R, Moreno V and Franceschi S. Male Circumcision, Penile Human Papillomavirus Infection, and Cervical Cancer in Female Partners. N Engl J Med, 346(15): 1105-1112.

10. See for example: Circumcision can control AIDS, but is India ready?, available at: http://timesofindia.indiatimes.com/NEWS/India/Circumcision_can_control_AIDS_but_is_India_re ady/articleshow/msid-1670374,curpg-1.cms

11. Prabhakara GN. Professional Medical Ethics. Paras Medical Publications 2006, 195.

12. Francis CM. Medical ethics in India: ancient and modern. Indian Journal of Medical Ethics, selected readings 1993-2003, November 2005, p.17.

13. Hellsten SK. Rationalising circumcision: from tradition to fashion, from public health to individual freedom. J Med Ethics 2004, 30:248-253.

14. Madhivanana P, Krupp K, Chandrasekaranb V, Karatc SC, Reingolda AL and Klausner JD. Acceptability of male circumcision among mothers with male children in Mysore, India. AIDS 2008, 22: 983-988.

15. See note 2 above.

16. Justin Martyr, Dialogue with Trypho. In particular, Chapters 16 and 19. Available at: http://www.ccel.org/ccel/schaff/anf01.toc.html

17. I will not be able to analyse this aspect further here, but it is interesting to note the escamotage that Justin found in order to preserve a continuity with the past of Christianity -Judaism- and yet be able to detach itself from it in the most productive way in terms of guaranteeing a neat separation: by accusing the rest of not being following God's will anymore. For more information on the subject see among others: Livesey NE, Theological Identity Making: Justin's Use of Circumcision to Create Jews and Christians, Journal of Early Christian Studies 2010, 18(1):51-79.

18. Böner K (ed.) Ausserlesene Bedenken der theologischen Facultät zu Leipzig, Leipzig, 1751. I have used the italian version: Parere della facoltà teologica di Lipsia dell'8 maggio 1714, L'Eco dei Tribunali: XIII Supplemento al Rovigo, 1856, n. 461, p.53.

19. Ecumenical Council of Florence (1438-1445) Available at: http://www.ewtn.com/library/councils/Florence.htm\#5. "Therefore it strictly orders all who glory in the name of Christian, not to practise circumcision either before or after baptism, since whether or not they place their hope in it, it cannot possibly be observed without loss of eternal salvation."

20. King PA, Caddy GM, Cohen SH, et al. Circumcision-maternal attributes. Pediatr Surg Int1989, 4:222-226.

21. Hodges FM. The history of phimosis from antiquity to the present. In: Denniston GC, Hodges FM, Milo MF, eds. Male and female circumcision: medical, legal and ethical considerations in pediatric practice. New York: Kluwer Academic, 1999, p.37-49. 
21a. Miller GP. Circumcision: cultural-legal analysis, Virginia Journal of Social Policy and the Law, 9, 2002, p.497-585.

22. Among the supporters of such a view there was Herbert Spencer who, in relation to the hygiene argument wrote that: "while the usage does not prevail among the most cleanly races in the world, it is common among the most uncleanly races." Principles of sociology, 1, Westport, Connecticut, Greenwood press, 1975, p.67.

23. Hutson JM. Circumcision: a surgeon's perspective. J Med Ethics 2004, 30: 238.

24. DeLaet DL. Framing Male Circumcision as a Human Rights Issue? Contributions to the Debate over the Universality of Human Rights. Journal of Human Rights 2009, 8: 405-426.

25. Germany to introduce circumcision law, http://www.guardian.co.uk/world/2012/oct/05/germany-introduce-circumcison-law 